\title{
WISATA RELIGI MAKAM GUNUNG JATI CIREBON SEBAGAI BUDAYA DAN MEDIA SPIRITUAL
}

\author{
Musrifah \\ ifahmusripah@yahoo.co.id
}

\begin{abstract}
The tomb of Gunung Jati is one of the graves of wali sanga on the island of Java. Gunung Jati tomb according to the community other than as a place of communication with the Creator is also regarded as a place for ngalap blessing, so that every day is never empty, especially in the month of maulid, especially on 12 Rabiul Awal most crowded pilgrims. The various cultures of the people who visit the tomb have their own goals and wishes, for example wanting to reach all their wishes and ideals, wealth, dating, career, having children and so on. The author raised the title because seeing the phenomenon of society from the traditional era until the postmodern period has not happened cultural shift, one of them is the culture of pilgrimage grave sali wali.

Based on the phenomenon that the authors see every month Rabi'ul Awal, especially on the 12th of Ramadan pilgrims more than usual day, because on that date the gates of the tomb opened so that the visitors can be allowed to enter, but also the palace of the elders also opened. The princesses and the sultanate of cirebon sultanate held a question, marching around the palace's environs to wash away the sultan's kris. That's what makes visitors more than usual. Tomb of Sunan Gunung Jati as one of the religious tourism visited by all walks of life, especially villagers often hold sali wali tour / pilgrimage of Wali Sanga that is visiting all guardians with the aim to synergize, dhikr with Allah through the guardian, also ngalap blessing of 7 kinds wells in the area of Cirebon.

This research uses qualitative research approach of reseachal library. Data-bricks used using primary and secondary data. The analysis used using content analysis.
\end{abstract}

Keyword: Religious Tourism Gunung Djati, Culture and Spiritual Grave

\begin{abstract}
Abstrak
Makam gunung Jati adalah salah satu makam wali sanga di pulau jawa . Makam gunung Jati menurut masyarakat selain sebagai tempat komunikasi dengan Pencipta juga dianggap sebagai tempat untuk ngalap berkah, sehingga setiap hari tidak
\end{abstract}


pernah sepi, terutama pada bulan maulid khususnya tanggal 12 Rabiul Awal paling rame peziarahnya. Bercorak ragam budaya masyarakat yang berkunjung ke makam mempunyai tujuan dan keinginan masing-masing,misalnya menginginkan tercapai segala keinginan dan cita-citanya, kekayaan, jodoh, karier,mempunyai anak dan lain sebagainya. Penulis mengangkat judul tersebut karena melihat fenomena masyarakat dari zaman tradisional sampai zaman posmodern belum terjadi pergeseran budaya, salah satunya adalah budaya ziarah makam wali sanga.

Berdasarkan fenomena yang penulis lihat setiap bulan Rabi'ul Awal terutama tanggal 12 Rabiul Awal peziarahnya melebihi hari biasa, karena pada tanggal tersebut pintupintu gerbang makam dibuka sehingga penggunjung diperbolehkan masuk, selain itu juga kraton kesepuhan juga dibuka. Para putri dan panggeran kesultanan cirebon menggadakan peranyaan, berbaris mengitari lingkungan keraton untuk membasuhi keris-keris peninggalan sultan. Peritiwa itulah yang membuat pengunjung lebih banyak dari hari biasa. Makam Sunan Gunung Jati sebagai salah satu wisata religi yang dikunjungi oleh semua lapisan masyarakat, terutama masyarakat desa sering mengadakan wisata wali sanga/ziarah Wali Sanga yaitu mengunjungi semua wali dengan tujuan untuk bersinergi, berdzikir dengan Allah melalui para wali, juga ngalap berkah dari 7 macam sumur yang ada di kawasan cirebon.

Penelitian ini menggunakan pendekatan penelitian kualitatif library reseachal. Databata yang digunakan menggunakan data-data primer dan sekunder. Analisis yang digunakan menggunakan content analysis. ${ }^{1}$

Kata Kunci: Wisata Religi Makam Gunung Djati, Budaya dan Spiritual

\section{A. Pendahuluan}

Sunan Gunung Jati adalah salah satu diantara sembilan orang penyebar agama Islam terkenal di pulau jawa yang dikenal dengan sebutan Wali Sanga. Makam Sunan Gunung Jati adalah makam pertama wali pertama yang permah penulis kunjungi karena tertarik ingin melihat suasana komplek makam Sunan Gunung Jati yang dikenal sebagai tempat wisata religi di Cirebon.

Kehidupan sunan Gunung Jati disamping sebagai pemimpin spiritual, sufi, mubaligh dan da’i pada zamannya , juga sebagai pemimpin rakyat, karena menjadi raja (sultan) di kesultanan cirebon. Bahkan sebagai Sultan pertama Kesultanan Cirebon yang semula bernama Keraton Pakungwati.

Nama aslinya Syarif Hidayatullah putra Maulana Ishaq Syarif Abdillah penguasa Kota Ismailiyah Arab Saudi, buak berasal dari Aceh seperti yang sering kita baca pada buku-buku sejarah Wali Sanga yang telah banyak beredar. Sunan Gunung Jati bukan Fatahillah, adalah berdasarkan kenyataan bahwa di samping sebelah kiri Makam Sunan Gunung Jati Syarif Hidayatullahal.Sunan Gunung Jati Syarif Hidayatullah hidup pada zaman Raden Patah sultan Demak pertama, Sedangkan Patahillah datang dari Aceh pada masa pemerintahan Sultan

1 Norman K,Denzin dan Y Vonna s. Lincoln, Handbook of Qualitative Research 1 ed. (Yogyakarta: Pustaka Pelajar, 2009) hal. 498 
Trenggono, Sultan ketiga setelah Dipati Unus. Satu hal yang sangat disayangkan, bahwa untuk bisa dibuktikan kebenaran akan adanya makam Fatahillah di samping makam Sunan Gunung Jati ini, pihak yang berwewenang di komplek pemakaman itu tidak mengizinkan sembarang orang memasukinya. Melainkan harus ada izin tertulis yang menandakan seseorang itu benar-benar mempunyai garis keturunan ke atasnya sampai kepada Sunan Gunung Jati Syarif Hidayatulahal. Karena itu sekedar untuk dipelajari dan dimaklumi. Maka berikut ini dikisahkan sekilas riwayat Sunan Gunung Jati dari asal keturunan, kelahiran, kehidupan dan sampai wafatnya berikut keadaan seoerti tradisi yang ada di sekitar tempat pemakamannya, komplek Pemakaman Gunung Sembung desa Astana Gunung Jati. ${ }^{2}$

Para ziarah Makam Sunan Gunung Jati ini hanya dibatasi sampai di depan pintu serambi mka yang pada waktu-waktu tertentu dibuka selama beberapa menit dan dijaga kalau-kalau ada seseorang yang memaksa masuk di sela-sela keramaian pengunjung. Dari pintu yang diberi nama SELAMAT TANGKEP ini terlihat puluhan tangga dan beberapa pintu lagi menuju $<$ akam Sunan Gunung Jati. ${ }^{3}$

Untuk peziarah bangsa Tiong Hoa disediakan ruangan khusus bagian barat serambi muka ini dengan maksud agar tidak merasa saling terganggu karena cara yang berlainan. Di samping itu karena posisi makan Nyi Ong Tien berada disebelah Barat makan Sunan Gunung Jati suaminya dan beberapa makam keluarga serta kerabat Keraton yang berada dalam satu cungkup bangunan paling atas dan bermemolo Kendi pertula. ${ }^{4}$

Tiga kali seminggu makam - makam itu di bersihkan dan diperbarui selalu denga rangkaian bunga yang segar oleh juru kunci yang bertugas . Sedangkan penggantian bunga itu dilakukan setiap hari senin, kamis dan hari jum'at. Pada hari senin dan kamis petugas masuk dari pintu dapur pesambangan pada pagi hari. Sedangkan pada hari jum'at petugas masuk melalui pintu serambi muka tempat pezizrzh di siang hari. Karena itu secara rutin pintu Selamat tangkep yang membuka pemandangan ke cungkup Makam Sunan Gunung Jati ini dibuka setiap har jum'at. Selain itu juga dibuka setiap acara penggantian petugas pada sore hari setiap setengah bulan.

Ziarah juga merupakan suatu hal yang mistis, sebagaimana pendapat Subandi (2009), merangkum berbagai pendapat para ahli yang mendefinisikan pengalaman mistis sebagai pengalaman spiritual atau pengalaman rokhani dimana orang merasakan bersentuhan dengan "sesuatu" yang bersifat Ketuhanan atau merasakan penyatuan seluruh dimensi dalam diri dan kehidupannya. Ada beberapa karakteristikoik pengalaman mistis yang sering ditemukan pada berbagai tradisi keagamaan, antara lain noetic, quality of unity, real, timelessness and spacelessness. ${ }^{5}$

Pengalaman mistis juga mempunyaikualitas neotik, artinya bahwa pengalaman mistis tidak hanya memiliki aspek pengalaman emosional saja, misalnya merasakan keterdekatan dengan

2 Hasan Basyari, Sekitar Komplek Sunan Gunung Jati Dan Sekilas Riwayatnya, (Cirebon, Zulfana, 1989)hal.5

3 Hasan Basyari, Sekitar Komplek Sunan Gunung Jati Dan Sekilas Riwayatnya, (Cirebon, Zulfana,1989) hal.23

4 Hasan Basyari, Sekitar Komplek Sunan Gunung Jati Dan Sekilas Riwayatnya, (Cirebon, Zulfana,1989) hal.23

5 Subandi, Psikologi Agama dan Kesehatan Mental, )Yugyakarta, Pustaka Pelajar, 2013) hal.73 
Tuhan tetapi juga mempunyai aspek kognitif. Pengalaman mistis sering juga menjadi sumber inspirasi, insight, pengetahuan, dan pencerahan yang dapat memberikan stimulus bagi fungsi kognitif sehingga dapat memberi rangsangan bagi timbulnya ide-ide baru yang tidak pernah terpikirkan sebelumnya. ${ }^{6}$

\section{Budaya Keislaman di Indonesia}

Pada saat Islam tersebar di Indonesia, Islam tidak bisa lepas dari budaya lokal yang sudah ada dalam masyarakat. Antara keduanya meniscayakan adanya sebuah dialog yang kreatif dan dinamis, hinga kemudian Islam dapat diterima sebagai agama baru tanpa harus menggusur budaya lokal yang sudah ada. Dalam posisi ini, budaya lokal yang mewujud dalam tradisi dan adat masyarakat setempat, tetap dapat dilakukan tanpa harus mencederai ajaran Islam. Begitu pula sebaliknya, Islam tetap bisa diajarkan tanpa harus mengganggu harmoni tradisi masyarakat. ${ }^{7}$

Dalam perjalannya, ternyata proses akulturasi dan asimilasi antara budaya lokal indonesia dengan ajaran Islam telah melahirkan berbagai tradisi kegamaan di kalangan masyarakat Indonesia seperti tahlilan,ziarah kubur, mujahadah, dan lain sebagainya. Dari segi pakaianpun umat Islam Indonesia berbeda (meski tidak sepenuhnya) dengan bangsa Arab yang identik dengan jenggot, jubah, dan surban. Di Indonesia umat Islam lebih banyak menggunakan sarung, peci, dan baju koko sebagai pakaian yang dianggap mencintrakan Islam.

Dalam konteks hari raya keagamaan, umat Islam Indonesia setiap tahunnya juga merayakan hari besar Islam yang merupakan bentuk peringatan terhadap berbagai peristiwa penting dalam sejarah Islam. Perayaan hari besar tersebut ditandai dengan kegiatan kebudayaan dan ibadah seperti pengajian, puasa, ceramah agama, mujahadah, dan lain sebagainya. ${ }^{8}$ Beberapa hari besar Islam yang diperingati oleh muslim di Indonesia diantaranya ; Tahun baru hijrah (1 Muharram), Hari Asyura (10 Muharram),Maulid Nabi Muhammad saw. (12 Rabi'ul Awal), Isra Mi'raj (27 Rajab), Idul Fitri (1 Syawal), Idul Adha (10 Zulhijjah), Adat Pernikahan, Penyamabutan Kelahiran Bayi, Ritual Kematian. Tradisi-tradisi yang lain juga ada diantaranya; Pelepasan dan penyambutan orang naik haji, dan rerresik Omahal.

Tradisi-tradisi tersebut merupakan bentuk ragam budaya Indonesia di satu sisi, dan juga gambaran betapa di dalamnya telah terjadi akulturasi dan asimilasi antara Islam dengan budaya lokal di sisi lain.Alih-alih mempertentangkan ragam tradisi tersebut, justru hal itu harus dilihat sebagai sebuah aset bangsa yang patut dilestarikan.

Agama dan budaya lokal merupakan dua entitas yang berbeda, namun tidak perlu dipertentangkan. Antara keduanya justru terdapat keniscayaan dialog yang tidak terhindarkan. Agama, mau tidak mau harus berdialog dengan budaya lokal agar agama tersebut diterima oleh masyarakat. Di Indonesia, dialog antara Islam dan budaya lokal menghasilkan varian Islam yang unik, khas, dan menarik serta kaya ragam budaya. Ragam budaya dan tradisi umat

6 Subandi, Psikologi Agama dan Kesehatan Mental, )Yugyakarta, Pustaka Pelajar, 2013) hal.74

7 Abdul Kholiq,dkk, Warna-warni Islam Potret Keragaman Umat Islam Di seluruh Dunia, (Yogyakarta, Qudsi Media, 2012) hal.140

8 Abdul Kholiq,dkk, Warna-warni Islam Potret Keragaman Umat Islam Di seluruh Dunia, (Yogyakarta: Qudsi Media, 2012) hal. 140-141 
Islam Indonesia sebagaimana telah disebutkan diatas merupakan bukti nyata bahwa telah tejadi persinggungan antara Islam dan udaya lokal yang kemudian menjelma menjadi beragam tradisi.

Tradisi-tradisi tersebut tetap terpeihara hingga kini, dan tentu saja dengan beberapa modifikasi Perubahan itu bisa dimungkinkan karena adanya dialektika yang etrus menerus antara masyrakat, tradisi, dan zaman yang menyertai proses itu berlansung, perubahan-perubahan tersebut menunjukan adanya dinamisasi Islam kultural di Indonesia, corak Islam yang berbasis pada nilai dan tradisi keindonesiaan bukanlah corak Islam yang statis, melainkan dinamis.

Dalam teori Clifford Geertz, berpendapat bahwa dengan mempergunakan argumenargumen tajam, dia menyatakan bahwa aktivitas kebudayaan manusia adalah sesuatu yang istimewa dan lain dari yang lain. Seandainya kita ingin "menjelaskannya” dengan cara-cara yang dipakai ilmuan eksakta dalam memahami alam, kita tidak akan mendapat apa-apa. Suka atau tidak, manusia pada kenyataannya memang berbeda dengan atom-atom atau serangga. Manusia hidup dalam suatu sistem makna yang sungguh kompleks, yang dinamakan para antropolog dengan "kebudayaan", Kalau kita ingin memahami aktivitas kebudayaan dan salah satu elememn terpenting di dalamnya adalah agama maka kita tidak punya pilihan lain kecuali menemukan metode-metode yang tepat. Dan metode-metode tersebut adalah "interpertasi". Dalam membicarakan manusia, kita lebih baik meninggalkan pendekatan "menjelaskan" perilaku mereka, seperti yang dilakukan oleh para ilmuan alam dalam menyelidiki sekawanan lebah atau sekelompok ikan. Maka tidaklah mengherankan bila ungkapan ini sering menjadi judul tulisan-tulisan Geertz. ${ }^{?}$

Realita masyarakat merupakan kenyataan dinamis dari berbagai cara pandang dan variasi perilaku individu, meskipun realita itu seolah-olah dikotomi dengan kenyataan lain, bahwa manusia adalah creator kehidupan sosial yang potensial dalam melakukan tindakan sesuai dengan hasratnya masing-masing. Seabagaimana konsep masyarakat dan budaya berlaku, maka secara langsung atau tidak potensi individual akan trjebak dalam sisten kehidupan normatif yang dapat menghentikan proses dinamis dan berbagai potensi yang dimaksud.

Menurut Hamka yang dikutip oleh Beni Ahmad Soebani, bahwa ajaran agama memiliki pengaruh yang besar dalam menatukan persepsi kehidupan masyarakat tentang semua harapan hidup. Sebagai salah satu arah kehidupan sosial yang proses permulaannya lebih sistematis dan mendarah daging. Dalam permulaan, perilaku sosial agama memasuki hati nurani manusia sehingga akal pikiran utama mencari makna hidup belum sempurna apabila substansi ajaran agama tidak dijadikan rujukan terpenting secara epistemologis maupun aksiologis. ${ }^{10}$

Pada komunitas beragama, mereka bukan hanya menyakini hal-hal yang realistik dan empirik, melainkan mereka pun meyakini hal-hal yang berbau mitos, kagaiban realitas, bahkan yang mustahil terlihat, mustahil untuk ditolak karena dzat ini mustahil adanya sama dengan sesuatu yang lain. Kebersamaan setiap orang yang beragama berdasar pada pemahaman, bahwa kebersamaan merupakan kewajiban manusia karena manusia telah ditaqdirkan sebagai makhluk

9 Daniel L Pals, Seven Theories Of Religion (Tujuh teori agama paling kompehenship), terj.Insyiak Ridwan Muzir, (Yogyakarta, IRGiSoD, 2012) hal. 328

10 Beni Ahmad Saebani, Sosiologi Agama, (Bandung,Refika Aditama, 2007) hal.2 
sosial. ${ }^{11}$

Durkheim juga memberikan definisi yang jelas mengenai apa yang menjadikan agama sebagai suatu praktek sosial, dengan menyatakan "fenomena religius secara alami terbagi menjadi dua ketegori dasar: keyakinan dan ritual. Topik pertama merupakan pendapat dan terdiri dari representasi ( simbol-simbol); yang kedua adalah cara berperilaku yang baku (praktik khusus)” . Apa yang kita yakini, atau apa yang kita sembah, dan bagaimana kita menyembah tercaku dalam ranah agama. Dan tidak mengherankan jika setelah penekanan Durkheim tentang sifat kolektif pada kehidupan sosial, keyakinan dan ritual keagamaan atau ritual bukanlah khas perseorangan, namun pasti merupakan milik bersama. ${ }^{12}$

\section{Tradisi Ziarah}

Pada dasarnya ziarah ke makam Sunan Gunung Jati adalah memanjatkan do'a kepada Alah SWT. Dengan menghadiahkan bacaan Al-Fatikhah kepada junjungan kita Nabi Muhammad SAW. Beserta para keluarga, sahabat, tabi'in, aulia, syuhada, dan sholikhin.Kemudian dikhususkan untuk Sunan Gungung Jati dan beberapa kerabatnya yang ikut menunjang pada masa beliau mengembangkan agama Islam di tanah Jawa.Khususnya di Jawa Barat. Sesudah itu dibacakan pada tahlil, tahmid, tasbih, takbir, sholawat atas Nabi dan beberapa surat Al-Qur'an. ${ }^{13}$

Namun demikian ada juga para peziarah yang melaksanakan lebih dari yang tersebut diatas sehingga ziarah kubur yang asal hukumnya sunnah menjadi seperti upacara tradisional. Hal ini sudah barang tentu berkaitan dengan upacara adat kraton yang masih melekat dalam kepercayaan masyarakat sekarang.

Beberapa hal yang menjadi tradisi ziarah makam Sunan Gunung Jati adalah:

a. Menyediakan bunga campur baur dan kemenyan atau hio,. Bunga campur baur dimaksudkan sebagai tanda belasungkawa dan penghormatan yang ditaburkan meskipun tidak langsung diatas makamnya. Hal ini juga pernah diisyaratkan Nabi SAW sewaktu menziarahi makam sahabatnya, beliau mengambil beberapa potong daun korma untuk diletakkan diatas pusarannya. Kemenyan atau hio yang dibakar dimaksudkan untuk menimbulkan aroma atau bau harum seantero ruangan walau hanya beberapa keping atau beberapa batang yang dibakar.

b. Karena letaknya yang berdampingan para ziarah menziarahi pula makam Syekh Dzatil Kahfi di Gunung Jati dan biasanya dilakukan setelah selesai dari makam Sunan Gunung Jati di Gungng Sembung. Mandi tujuh sumur, yaitu sumur Kanoman, Kasepuhan, Waluyajati, masjid, Tegangpati, Jalatunda, dam Kejayan. Empat sumur, masing-masing; Kanoman, Kasepuhan, Walujayanti dan Sumur Masjid berlokasi di kompleks pemakaman Gunung Sembung, sedangkan tiga sumur lagi ialah Tegangpati, Jalatunda dan Kejayan berada di komplek pemakaman Gunung Jati. Ramainya peziarah mandi di tujuh sumur ini selain pada

11 Beni Ahmad Saebani, Sosiologi Agama, (Bandung,Refika Aditama, 2007) hal.6

12 Bryan S. Turner, Teori Sosial Dari Klasik Sampai Postmodern, terj.L. Setiyawati dan Roh Shufiyati, (Yogyakarta, Pustaka Pelajar, 2012) hal. 695

13 Hasan Basyari, Sekitar Komplek Sunan Gunung Jati Dan Sekilas Riwayatnya, (Cirebon, Zulfana,1989) hal.28 
peringatan tradisional Maulud, juga pada hari Jum'at yang jatuh pada pertengahan bulan Hijriah, yaitu tanggal 14,15 dan 16.

c. Memasuki ambang pintu Gua Sikendi di puncak Gunung Jati dan menziarahi beberapa petilasan ( bukan kuburan aslinya) Sunan Giri, Sunan Bonang, dan Wali Sanga. Juga ada satu kuburan yang diziarahi oleh mereka yang sedang menanggung urusan, baik perdata maupun pidana. Kuburan itu disebut makam Badar yang letaknya di sebeah selatan komplek Makam Sunan Gunung Jati. Dan beberapa hal lagi yang sejenis tradisi spiritual. ${ }^{14}$

Disamping pengunjung yang berniat ziarah dengan melaksanakan tradisi ziarahnya itu ada pada pengunjung yang sekedar melihat - lihat sekitar komplek itu karena tertarik akan keadaan dan tradisi yang pernah di degar dan dilihatnya dari media komunikasi, mereka ini biasanya arkeologi dan budayawan. Apalagi belakangan ini komplek pemakaman Gunung Sembung dan Gunung Jati sedang dipromosikan sebagai objek pariwisati di wilayah Cirebon, sehingga minat pengunjung yang hanya untuk melihat-lihat suasana hampir menyamai pengunjung yang benar-benar akan ziarahal. Untuk itu lebih mengena dengan sebutan pengunjung dari pada dengan sebutan peziarahal.

Ziarah atau mengunjungi Makam Gunung Jati bisa dengan langsung sendirian atau rombongan melalui jalan yang telah ditentukan dan minta izin lebih dahulu kepada penjaga atau juru kunci yang sedang bertugas. Namun demikian bagi pengunjung dan peziarah dianjurkan mengikuti ritual atau aturan yang dibuat oleh juru kunci diantaranya adalah:

a. Berdo'a atau memohon hanya kepada Allah SWT.

b. Tidak mendewa-dewakan sesuatu benda sehingga menjurus kepada perbuatan musyrik.

c. Tidak mempengaruhi apalagi mengganggu sesama pengunjung yang berdo'a atau berdzikir dengan caranya sendiri, kecuali bila caranya itu mengganggu orang lain.

d. Tidak mengganggu barang-barang peninggalan dahulu yang terdapat di sekeliling Pesambangan. ${ }^{15}$

Di samping empat hal yang perlu diingat oleh setiap pengunjung, juga haruslah dihayati dan diamalkan Wasiat Sunan Gunung Jati yang berbunyi: "Ingsun titip tajug lan fakir - miskin" Aku titipkan masjid/mushola dan fakir miskin. Maksudnya beliau menitipkan tempat shalat dan orang fakir miskin adalah agar bisa senantiasa menegakkan sholat dan orang fakir miskin itu ialah agar kita senantiasa menegakkan shalat dan membayar zakat.

Peziarah Makam sunan Gunung Jati diperkenankan bermalam sehari, dua hari sampai seminggu lamanya dengan ketentuan memenuhi persyaatan untuk selama bermukim. Ketentuan yang berlaku peziarah yang bermalam antara lain adalah menyerahkan KTP atau Tanda Pengenal lainnya kepada petugas untuk kemudian disampaikan kepada pemerintah setempat dan dikembalikan lagi bila saatnya pulang. Selain itu harus punya bekal untuk makan selama bermukim dan tersedia pula untuk ongkos pulang. Tujuan mereka bermukim kebanyakan untuk berkhalwat sambil berpuasa hingga khusyu tidak terganggu oleh keluarga seperti kalau

14 Hasan Basyari, Sekitar Komplek Sunan Gunung Jati dan Sekilas Riwayatnya, (Cirebon, Zulfana,1989) hal.28-29

15 Hasan Basyari, Sekitar Komplek Sunan Gunung Jati dan Sekilas Riwayatnya, (Cirebon, Zulfana,1989) hal.29 
di rumahal. Tetapi bukanlah suatu kebaikan apabila keluarga yang ditinggalkan tidak tinggali nafkah yang cukup sehiingga dirinya merasa tentram. Dan tidak diperkenankan puasa terus menerus karena alasan tidak ada bekal atau lainnya. Hal ini dikarenkan bisa menjadi beban petugas setempat bila terjadi hal-hal yang membahayakan disamping ibarat apa yang disabdakan oleh Nabi ' kekurangan atau kelaparan itu bisa menjurus kepada kekufuran. ${ }^{16}$

Subandi (2009 (Menemukan bahwa subyek yang melakukan dzikir dengan teknik tertentu, menemui berbagai bentuk pengalaman beragama. Dari hasil data-data diperoleh 18 tema pengalaman beragama antara lain:

1) Timbulnya gerakan-gerakan otomatis.

2) Penyucian diri.

3) Penemuan kebenaran.

4) Pemahaman baru tentang ajaran-ajaran agama.

5) Keakraban dan kedekatan dengan Tuhan.

6) Transisi.

7) Peningkatan ritual ibadahal.

8) Hilangnya rasa ke-aku-an.

9) Pengalaman penyembuhan.

10) Pengalaman yang sulit diungkapkan secara verbal (ineffable)

11) Pengalaman menjangkau masa depan.

12) Pengalaman yang berhubungan dengan problem kehidupan sehari-hari.

13) Pembaharuan moralitas.

14) Gangguan dari makhluk lain.

15) Pengalaman yang berkaitan dengan perubahan kesadaran atau altered states of consciousness (ASC)

16) Pengalaman yang berkaitan dengan suasana emosi.

17) Perasaa diatur oleh Tuhan.

18) Mendapatkan petunjuk dari Tuhan. ${ }^{17}$

Berdasarkan kesamaan Isi dari tema-tema pengalaman beragama yang telah disebutkan di atas, maka tema-tema yang telah disebutkan di atas dapat kalsifikasikan sebagai berikut: (1) Pengalaman fisiologis, (2)Pengalaman sosial psikologis, (3) Pengalaman para -psikokogis, dan (4) Pengalaman spiritual/kerohanian.

Berkaitan dengan dzikir Meadow \& Kahoe (1984) yang dikutip Subandi, banhwa pengalaman dzikir sebagaimana diungkapkan dalam penelitiannya memiliki sejumlah kesamaan dengan pengalaman mistis yang dibahas dalam berbagai literatur.Kesamaan itu diantaranya ditujukkan oleh beberapa karakteristik; dzikir dan pengalaman mistis menpunyai kualitas sebagai sumber pengetahuan (neotik); keduanya sulit dilukiskan dengan sesuatu yang suci (holy) keduanya bersifat pasif (passive); keduanya melibatkan hilangnya dimensi ruang dan waktu

16 Hasan Basyari, Sekitar Komplek Sunan Gunung Jati dan Sekilas Riwayatnya, (Cirebon, Zulfana, 1989) hal.30 17 Subandi, Psikologi Agama dan Kesehatan Mental, (Yogyakarta, Pustaka Pelajar,2013) hal. 77-78 
(timelessness and spaceletness) dan keduany menimbulkan suasana batin positif yang mendalam. ${ }^{18}$

Kualitas suci dari pengalaman dzikir itu jelas dari pemahaman partisipan mengenai pengalamn mereka dalam konteks religius, yaitu karunia dari Allahal. Hal tersebut ditujukkan oleh seorang partisipan yang merasakan adanya kesucian di mana dia merasakan "Kemakhlukan"nya di hadapan "Sang pencipta".

\section{B. Kesimpulan}

Kota Cirebon merupakan salah satu kota di Jawa Barat yang cukup terkenal berkat adanya Makam Syarif Hidayatullah, seorang mubaligh, pemimpin spiritual, dan sufi yang juga dikenal dengan sebutan Sunan Gunung Jati. Makam ini terdiri dari sembilan tingkat, dan pada tingkat kesembilan inilah Sunan Gunung Jati dimakamkan.Sedangkan tingkat kedelapan ke bawah adalah makam keluarga dan para keturunannya, baik keturunan yang dari Kraton Kanoman maupun keturunan dari Kraton Kasepuhan. Makam yang menempati lahan 4 hektar ini merupakan obyek wisata ziarah yang banyak dikunjungiboleh para wisatawan baik dari Cirebon maupun kota-kota sekitarnya. Kedatangan para peziarah itu biasanya berlangsung pada waktuwaktu tertentu seperti jum'at Kliwon, peringatan maulid Nabi Muhammad SAW, ritual Brebeg Syawal, ritual Grebrg Rayagung, dan ritual pencucian jimat.

Makam Sunan Gunung Jati sebagai budaya Islam di Indonesia khususnya di Jawa adalah sebagai tempat wisata religi, juga sebagai tempat penelitian, bercorak ragam kepentingan dan tujuan peziarah mendatangi Makam Sunan Gunung Jati Cirebon. Di samping ketertarikan para peziarah Makam Sunan Gunung Jati sebagai media / tempat yang sakral dalam kegiatan spiritual dengan melaui doa-doa, tahlil, dzikir, tabur bunga, dan lain sebagainya dengan mengikuti aturan-aturan yang dibuat oleh juru kunci.

\section{Bibiliografi}

Abdul Hamid,Pemikiran Modern Dalam Islam,Bandung,Pustaka Setia,2010.

Agus Abdul Rahman,Psikologi Sosial,Jakarta, RajaGrafindo Persada,2014

Abdul Kholiq, Warna-Warni Islam Protret Keragaman Umat Islam Di Seluruh Dunia, Yogyakarta, Qudsi Media,2012.

Beni Ahmad Soebani, Sosiologi Agama, Bandung, Refika Aditama,2007.

Bryan S. Turner, Teori Sosial Dari Klasik Sampai Postmodern, terj.L. Setiyawati dan Roh Shufiyati, Yogyakarta, Pustaka Pelajar,2012

Hasan Basyari, Sekitar Komplek Sunan Gunung Jati Dan Sekilas Riwayatnya, Cirebon,

18 Subandi, Psikologi Dzikir, (Yogyakarta, Pustaka Pelajar, 2009) hal. 222-223 
Zulfana, 1989

Irwan Abdullah,Konstruksi dan Reproduksi Kebudayaan, Yogyakarta, Pustaka Pelajar,2007. Jalaludin, Psikologi Agama,Jakarta, RajaGrafindo Persada,2011.

Subandi , Psikologi Dzikir,Yogyakarta, Pustaka Pelajar, 2009

Psikologi Agama dan Kesehatan Mental,Yogyakarta, Pustaka Pelajar,2016 